UNIVERSIDADE FEDERAL DO AMAZONAS

FACULDADE DE TECNOLOGIA - FT

DEPARTAMENTO DE ENGENHARIA DE PRODUÇÃO

UFAM

\title{
AVALIAÇÃO ERGONOMICA NA AREA ADMINISTRATIVA DO HOSPITAL SANTA JULIA DE MANAUS
}

Deborah de Sousa Vinhote (21000309)- Aluna

deborahvinhote@hotmail.com

Nilson Barreiros - Orientador nilbarr@gmail.com 


\title{
Resumo
}

O conceito de Ergonomia se aplica à qualidade de adaptação de uma máquina ao seu operador, proporcionando um eficaz manuseio e evitando um esforço extremo do trabalhador na execução do trabalho. Este artigo tem como objetivo geral de mostrar aos setores responsáveis e diretoria do Hospital Santa Júlia que está havendo ausência de aplicação das técnicas de adaptação dos elementos ergonômicos no ambiente de trabalho sendo este o problema e utilizar soluções ergonômicas no local de trabalho é uma iniciativa que pode aumentar significativamente os níveis de satisfação, eficácia, eficiência do trabalhador e assim diminuindo o índice de absenteísmo e o afastamento pelo INSS por motivos ergonômicos.

Aparentemente os fatores relacionados ao layout e mobiliário que constatamos por meio de visitas técnicas, fotografias, depoimentos que foram validados, fazem com que os colaboradores trabalhem com posturas forçadas. No setor do envio de contas médicas: estão trabalhando com excesso de carregamento de pesos, Layout inadequado, trazendo assim conseqüências para a saúde dos colaboradores vale ressaltar que todos que realizaram o questionário relataram que sentem dores por questões ergonômicas no final da sua jornada de trabalho.

Pretende-se estar contribuindo a formação de um senso crítico quanto ao tema, evidenciando sua importância e aplicação, inicialmente às atividades de trabalho e estendido a todas as esferas da vida. Portanto, este projeto teve como objetivo fornecer os elementos necessários para o entendimento dos conceitos básicos da ergonomia, apresentando que já é a hora de ser preocupar com a saúde e bem-estar dos colaboradores do setor administrativo desta unidade de saúde.

Palavras-chave: Hospital Santa Júlia, ergonomia, saúde.

\begin{abstract}
The concept of Ergonomics applies to the quality of a machine's adaptation to its operator, providing effective handling and avoiding extreme worker effort when performing work. This article aims to show to the responsible sectors and board of the Santa Julia Hospital that there is an absence of application of the techniques of adaptation of ergonomic elements in the workplace. This is the problem and to use ergonomic solutions in the workplace. Can significantly increase levels of worker satisfaction, effectiveness, efficiency and thus decreasing the absenteeism rate and the dismissal by the INSS for ergonomic reasons.

Apparently the factors related to layout and furniture that we found through technical visits, photographs, testimonials that have been validated, make employees work with forced postures. In the field of medical bills: are working with excess weight, inadequate layout, thus having consequences for the health of employees it is noteworthy that everyone who completed the questionnaire reported that they feel pain due to ergonomic issues at the end of their workday .

It is intended to contribute to the formation of a critical sense on the subject, highlighting its importance and application, initially to work activities and extended to all walks of life. Therefore, this project aimed to provide the necessary elements for the understanding of the basic concepts of ergonomics, presenting that it is time to be concerned with the health and well-being of the employees of the administrative sector of this health unit.
\end{abstract}

Keywords:Santa Julia Hospital, ergonomics, health.

\subsection{Introdução}

Atualmente, o assunto mais mencionado é sobre a saúde, muitos têm se preocupado com ela e assim trazendo para o ambiente de trabalho nada melhor do que falarmos sobre a ergonomia, como o setor administrativo é um setor que passa a maior parte do tempo sentado por muito tempo, é algo com que se preocupar, tais como: postura, iluminação, os ruídos e a temperatura do ambiente são geralmente conhecidas como agentes 
causadores de males da saúde física e mental (Migalhas-2016).

O conceito de Ergonomia se aplica à qualidade de adaptação de uma máquina ao seu operador, proporcionando um eficaz manuseio e evitando um esforço extremo do trabalhador na execução do trabalho. As lesões por esforço repetitivo (LER) são um dos problemas físicos mais comuns que pode causar limitações ou mesmo a incapacidade de trabalhar, por exemplo. (Significados-2017)

Este artigo tem como objetivo geral de mostrar aos setores responsáveis e diretoria do hospital que está havendo ausência de aplicação das técnicas de adaptação dos elementos ergonômicos no ambiente de trabalho sendo este o problema e utilizar soluções ergonômicas no local de trabalho é uma iniciativa que pode aumentar significativamente os níveis de satisfação, eficácia, eficiência do trabalhador e assim diminuindo o índice de absenteísmo e o afastamento pelo INSS por motivos ergonômicos.

Com objetivos específicos:

- Observar e descrever o posto de trabalho e suas funções correspondentes;

- Avaliar a questão da biomecânica nas diferentes atividades;

- Estudar as condições de trabalho físico e mental dos colaboradores;

- Levantamento das relações interpessoais nos grupos;

- Identificar situações de risco quanto ao mobiliário, equipamentos, ferramentas e atitudes posturais inadequadas nos setores da empresa;

- Criar sensibilização para a cultura ergonômica dentro da empresa, através dos resultados da Análise Ergonômica do Trabalho;

- Sugerir soluções ergonômicas visando redução de queixas e melhora do desempenho e bem-estar dos colaboradores do Hospital Santa Julia;

- Atender a NR 17 do Ministério do Trabalho e Emprego.

\subsection{Referenciais Teóricos}

\subsection{História Organizacional}

O Hospital Santa Júlia iniciou suas atividades em 1980, desde o início teve seu foco principal na humanização e no cuidado com os pacientes. Faz questão de adquirir e utilizar os mais modernos equipamentos existentes no mercado, possibilitando ao seu corpo clínico a utilização dos mais modernos recursos tecnológicos disponíveis na área de saúde, para diagnóstico e para o tratamento de diversas outras patologias.

Por esse motivo, é o maior e mais completo hospital da região norte onde reúne todos os serviços médico-hospitalares desde os serviços básicos ambulatoriais, até os serviços de alta complexidade como a U.T.I (Unidade de Terapia Intensiva).

Em 2014, foi recomendado pela empresa credenciada Vanzolini, a receber o certificado de Acreditação Nível 1 da ONA (Organização Nacional de Acreditação), confirmando o compromisso em ser referência nacional em alta complexidade. Além dos serviços de destaques como transplante de rins, cirurgias cardíacas e coronarianas, neurocirurgia e ortopedia, estão com uma moderna Unidade de Oncologia, com tratamento completo e aparelhagem de última geração. (SANTA JULIA)

- Foi o primeiro a realizar procedimentos endoscópicos na área de urologia;

- Foi o primeiro hospital da região a realizar fertilização in-vitro (bebês de proveta);

- Realizou em 22 de junho de 1995, o primeiro transplante do Amazonas e foi o primeiro a implantar o Centro de Transplante de Rim no Norte do Brasil;

- Foi o primeiro na realização de transplante de rins com doador falecido, em 08 de julho de 2011.

Missão: Prestar assistência à saúde com humanização e excelência, mantendo pioneirismo nos avanços tecnológicos e científicos. 
Visão: Ser referência nacional em alta complexidade.

Valores: Vida em primeiro lugar, integridade, honestidade, foco no cliente, desenvolvimento profissional, transparência, responsabilidade social, segurança e determinação.

Serviços Prestados: Pronto Atendimento, Consultas Médicas, Exames de Imagem, Exames de Laboratório, Centro Cirúrgico, UTI Neonatal e Pediátrica, UTI Coronariana, UTI Geral, Hemodinâmica, Unidade de Hemodiálise, Unidade de Oncológica.

Especialidades: Neurocirurgia, Urologia, Cardiologia, Cirurgia Geral, Cirurgia Plástica,Gastroenterologia,Geriatria,Hematologia,Neurologia,Ortopedia,Oftalmologia, Otorrinolaringologia

Dentre as áreas assistenciais, refere-se ao colaborador que trata diretamente com paciente e administrativa que é responsável pela parte burocrática. Com relação à área administrativa temos os seguintes setores: Qualidade, Ouvidoria, Tecnologia da Informação, Comercial, Central de Autorização, Engenharia Clínica, Serviços de Nutrição e Dietética, Serviço Social, Sesmt, Regras de Negócio, Análise e Envio de Contas Médicas, Contas à receber, Contas à pagar, Faturamento, Financeiro, Recursos Humanos, Tesouraria, Custos, Almoxarifado Central, Almoxarifado OPME, Compras, CCIH, SAME, Recurso de Glosa, Auditoria de Contas Médicas.

O setor administrativo difere do setor assistencial uma vez que o colaborador passa a maior parte do tempo na mesma posição sendo sentado, fazendo assim que o mesmo adquira problemas de saúde por fatores ergonômicos. Para abordarmos o problema, primeiramente temos que entender melhor o assunto temos que inicialmente falar sobre ergonomia e conceituar seu objetivo, classificação e seus tipos de intervenção.

\subsection{A História da Ergonomia}

É uma palavra de origem grega composta de Ergos (trabalho) e Nomos (normas) formam a palavra que designa a ciência responsável por estudar as condições de trabalho. Ainda que o nascimento da ergonomia tenha oficialmente ocorrido no século $\mathrm{XX}$, considera-se que, desde a pré-história, os homens buscam técnicas para adaptar o trabalho às condições humanas (e não o contrário). (BEECORP-2017)

Isso é muito próximo da ergonomia que utilizamos hoje em dia, embora atualmente haja uma preocupação além dessas: a necessidade de afastar os riscos de acidente, de aumentar a produtividade e de gerar mais confiança na empresa perante a sociedade. Apesar de o conceito já ser aplicado, o termo só foi utilizado pela primeira vez no ano de 1857 , pelo polonês Wojciech Jarstembowsky. Ele a definia como "uma ciência do trabalho que requer que entendamos a atividade humana em termos de esforço, pensamento, relacionamento e dedicação". (BEECORP-2017)

\subsubsection{Conceito da Ergonomia}

Consiste no conjunto de disciplinas que estuda a organização do trabalho no qual existem interações entre seres humanos e máquinas, é o estudo da adaptação do trabalho ao homem. (Nathalia Segadas-2017)

\subsubsection{Objetivo da Ergonomia}

Desenvolver e aplicar técnicas de adaptação de elementos do ambiente de trabalho ao ser humano, com o objetivo de gerar o bem-estar do trabalhador e consequentemente aumentar a sua produtividade. A ergonomia visa em primeiro lugar a saúde, segurança e satisfação do trabalhador. 


\subsubsection{Classificação da Ergonomia}

A ergonomia é classificada por diferentes tipos de acordo com a sua contribuição. São elas: Ergonomia Física, Ergonomia Cognitiva e Ergonomia Organizacional. (Ana Flavia Oliveira)

- Ergonomia Física: está relacionada com as características da anatomia humana, antropometria, fisiologia e biomecânica em sua relação à atividade física. Os tópicos relevantes incluem o estudo da postura no trabalho, manuseio de materiais, movimentos repetitivos, distúrbios músculo-esqueletais relacionados ao trabalho, projeto de posto de trabalho, segurança e saúde. (ABERGO-2000)

- Ergonomia Cognitiva: também conhecida como engenharia psicológica. A palavra "cognitiva" sugere uma relação com um conjunto de processos mentais, entre eles a percepção, a atenção, a cognição, o controle motor e o armazenamento e recuperação de memória. (Significados-2017)

Analisa o impacto que esses processos têm na interação do ser humano e outros elementos dentro de um sistema. Algumas áreas específicas são: carga mental de trabalho, vigilância, tomada de decisão, desempenho de habilidades, erro humano, interação humano-computador e treinamento. (Significados-2017)

- Ergonomia Organizacional: é a macro ergonomia pois ela engloba o entendimento do gerenciamento de recursos de pessoas, projetos de trabalho, cultura organizacional, forma de comunicação, organização em rede, gestão de qualidade. A macro ergonomia não se constitui em sistema fechado, já que exige contínuo desenvolvimento, aplicação e validação de dados. (Monica Pinheiro)

\subsubsection{Tipos de Intervenção da Ergonomia:}

- Concessão de postos e métodos de trabalho, ferramentas, máquinas e mobiliário (CRPG-2012)

- Correção de problemas identificados através de metodologias próprias(CRPG2012)

- Sensibilização, informação e formação sobre os métodos e técnicas mais adequados para realizar as suas tarefas. (CRPG-2012)

\subsection{Norma Regulamentadora 17}

A relação entre a ergonomia e o ambiente de trabalho tem a norma regulamentadora NR-17 (Ergonomia) do Ministério do Trabalho e Emprego. É regulamentado pela Portaria $\mathrm{N}^{\mathrm{0}} 3.214$, de 08 de junho de 1978, que aprova as normas regulamentadoras do Capítulo V, Título II, da Consolidação das Leis do Trabalho - CLT, relativas à Segurança e Medicina do Trabalho.

Tendo como objetivo estabelecer os parâmetros que permitam a adaptação das condições de trabalho, às características psicofisiológicas dos trabalhadores, de modo a proporcionar um máximo de conforto, segurança e desempenho eficiente. (Areaseg2017).Abordando os assuntos: Levantamento, Transporte e Descarga Individual de Materiais, Mobiliário dos Postos de Trabalho, Equipamentos dos Postos de Trabalho, Condições Ambientais de Trabalho, Organização do Trabalho.

\subsection{Metodologia de Coleta e Análise de Dados}

Relacionando este projeto ergonômico ao tipo de pesquisa que será realizado são: Método qualitativo: Além de compreender e interpretar comportamentos e tendências, o instrumento também é usado identificar hipóteses para um problema e descobrir as percepções e expectativas dos colaboradores (Hugo Rocha,2013). Pesquisa Exploratória: A pesquisa exploratória procura explorar um problema, de modo a fornecer informações para uma investigação mais precisa (Juliana Diana,2017). Logo para adquirir todos os dados necessários sobre o tema abordado foi elaborado as seguintes etapas: 
- $\quad$ Consultoria Inicial: levantamento de dados da empresa com setor RH, saber os setores administrativos que compõe parte do hospital.

- Observação dos postos e postura de trabalho: observação de cada posto de trabalho, associada com troca de informações com os colaboradores;

- Aplicação do Questionário: Tendo como objetivo coletar e analisar os dados com a percepção dos colaboradores com relação à ergonomia. Para elaboração do questionário foi utilizado a ferramenta ergonômica Check List de Couto, conforme ilustrado na figura 1.

\begin{tabular}{|c|c|}
\hline \multicolumn{2}{|c|}{$\begin{array}{c}\text { QUESTIONÁRIO } \\
\text { Todas as informações serão confidenciais e tratadas para fins de pesquisa }\end{array}$} \\
\hline \multicolumn{2}{|c|}{ DADOS DO ENTREVISTADO } \\
\hline \multicolumn{2}{|l|}{ Nome: } \\
\hline \multicolumn{2}{|l|}{ Cargo: } \\
\hline \multicolumn{2}{|l|}{ Setor: } \\
\hline \multicolumn{2}{|l|}{ Tempo de trabalho nesta empresa: } \\
\hline \multicolumn{2}{|l|}{ AVALIAÇÃO DA CADEIRA } \\
\hline Cadeira estofada? & ( ) $\operatorname{Sim}($ ( ) Não \\
\hline Altura regulável? & ( ) Sim ( ) Não \\
\hline Acionamento fácil da regulagem da altura? & ( ) $\operatorname{Sim}($ ( ) Não \\
\hline Largura da cadeira de dimensão correta? & ( ) $\operatorname{Sim}($ ) Não \\
\hline $\begin{array}{l}\text { Assento na horizontal, não jogando o corpo do funcionário para } \\
\text { trás? }\end{array}$ & ( ) $\operatorname{Sim}($ ) Não \\
\hline Borda do assento arredondada? & ( ) $\operatorname{Sim}($ ( ) Não \\
\hline Apoio dorsal com regulagem da inclinação? & ( ) $\operatorname{Sim}($ ) Não \\
\hline Apoio dorsal fornece um suporte firme? & ( ) $\operatorname{Sim}($ ) Não \\
\hline Forma do apoio acompanhando as curvaturas normais da coluna? & ( ) Sim ( ) Não \\
\hline Regulagem da altura do apoio dorsal? & ( ) $\operatorname{Sim}($ ) Não \\
\hline Giratória? & ( ) $\operatorname{Sim}($ ) Não \\
\hline Rodízios não muito duros nem muito leves? & ( ) $\operatorname{Sim}($ ) Não \\
\hline Existe apoio para os membros superiores? & ( ) Sim ( ) Não \\
\hline Os apoios para membros superiores são arredondados? & ( ) Sim ( ) Não \\
\hline A cadeira está em ótimo estado? & ( ) $\operatorname{Sim}($ ) Não \\
\hline \multicolumn{2}{|l|}{ MESA DE TRABALHO } \\
\hline Altura apropriada? & ( ) $\operatorname{Sim}($ ) Não \\
\hline A borda da mesa é arredondada? & ( ) $\operatorname{Sim}($ ) Não \\
\hline Espaço para as pernas largos? & ( ) $\operatorname{Sim}($ ) Não \\
\hline Tem espaço suficiente para colocar os materiais de trabalho? & ( ) $\operatorname{Sim}($ ( ) Não \\
\hline A mesa está em ótimo estado? & ( ) $\operatorname{Sim}($ ) Não \\
\hline \multicolumn{2}{|l|}{$\begin{array}{l}\text { APOIO PARA OS PÉS } \\
\end{array}$} \\
\hline $\begin{array}{l}\text { Possui apoio para os pés? (Caso resposta seja negativa, pode } \\
\text { prosseguir para o próximo tópico) }\end{array}$ & ( ) $\operatorname{Sim}($ ( ) Não \\
\hline Largura suficiente? & ( ) $\operatorname{Sim}($ ) Não \\
\hline $\begin{array}{l}\text { Altura regulável? Ou disponível mais de um modelo, com alturas } \\
\text { diferentes? }\end{array}$ & ( ) $\operatorname{Sim}($ ) Não \\
\hline Inclinacão ajustável? & ( ) $\operatorname{Sim}($ ) Não \\
\hline Pode ser movido para frente ou para trás no piso? & ( ) $\operatorname{Sim}($ ) Não \\
\hline Desliza facilmente no piso? & ( ) $\operatorname{Sim}($ ) Não \\
\hline \multicolumn{2}{|l|}{ AVALIACC̃̃O DO TECLADO } \\
\hline As teclas têm forma côncava, permitindo o encaixe do dedo? & ( ) Sim ( ) Não \\
\hline Tem mecanismo de inclinação? & ( ) $\operatorname{Sim}($ ) Não \\
\hline Teclado está em ótimo estado? & ( ) Sim ( ) Não \\
\hline As teclas têm dimensões corretas? & ( ) $\operatorname{Sim}($ ) Não \\
\hline Apresenta algum defeito? & ( ) $\operatorname{Sim}($ ) Não \\
\hline \multicolumn{2}{|c|}{ AVALIACÃO DO MONITOR DE VÍIEO } \\
\hline Sua altura está adequada? & ( ) $\operatorname{Sim}($ ) Não \\
\hline $\begin{array}{l}\text { Há mecanismos de regulagem de altura disponível e este ajuste } \\
\text { pode ser feito facilmente? }\end{array}$ & ( ) $\operatorname{Sim}($ ) Não \\
\hline Tem controle de brilho e de contraste dos caracteres? & ( ) $\operatorname{Sim}($ ) Não \\
\hline A imagem permanece claramente definida a luminância máxima? & ( ) $\operatorname{Sim}($ ) Não \\
\hline
\end{tabular}




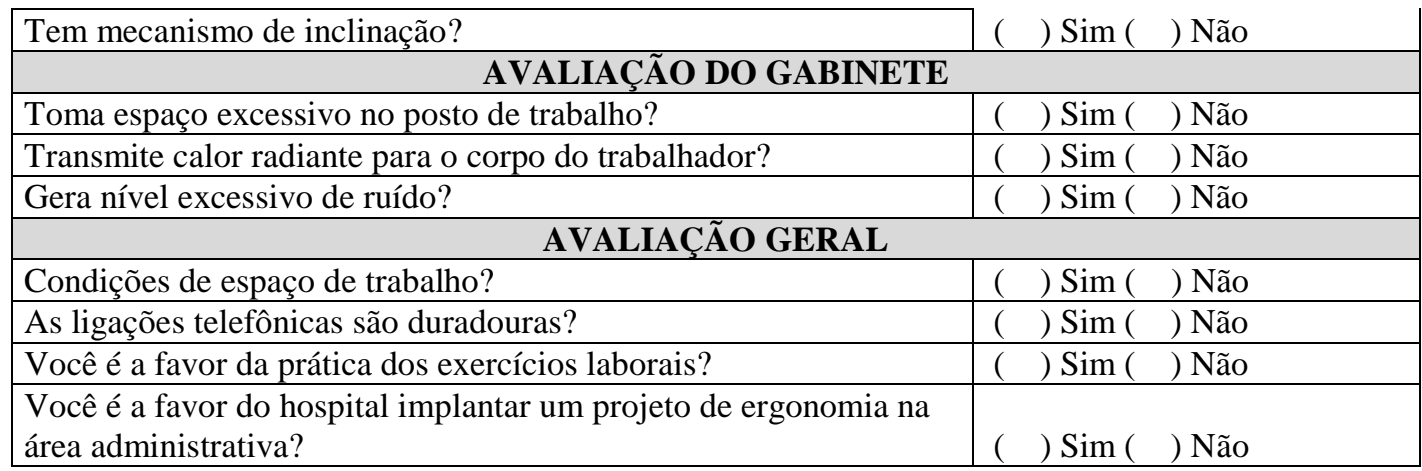

Tabela 1-Questionário Aplicado aos colaboradores

Fonte: SlideShare (2014)

Check List Couto: é uma avaliação simplificada do fator biomecânico, no risco para distúrbios musculoesqueléticos de membros superiores relacionados ao trabalho. Tendo como objetivo combater e corrigir as possíveis ocorrências de LER/ DORT. (Anabel2014)

- Principais causas de LER/DORT:

- Posto de trabalho inadequado,

- Atividades no trabalho que exijam força excessiva com as mãos;

- Posturas inadequadas;

- Repetição sistemática de um mesmo padrão de movimento;

- Falta de orientação.

Ao fim do questionário somam-se as respostas e tiram-se a porcentagem delas comparando, em seguida, com um padrão que estabelece os critérios de avaliação que relata as condições ergonômicas em cada posto de trabalho abordado pelo checklist. Fotografias apresentadas nas avaliações dos postos de trabalho são meramente para representar o posto avaliado. Foram também considerados todos os requisitos da Norma Regulamentadora $\mathrm{n}^{\circ} 17$.

Para analisar os resultados que serão obtidos com o questionário devem-se verificar os critérios de cada item pesquisado, somando os itens a cada resposta, como mostra a tabela 2, após o somatório de todos os pontos de cada item avaliar a condição ergonômica conforme critério de interpretação da tabela 3, com isso foi escolhido aleatoriamente quatro setores da área administrativa e dois funcionários de cada uma, sendo elas: Recurso Humanos, Central de Autorização, Faturamento e Envio de Contas Médicas.

\begin{tabular}{|l|l|}
\hline AVALIAÇÃO DA CADEIRA & SIM (1 PONTO) / NÃO (0 PONTO) \\
\hline MESA DE TRABALHO & SIM (1 PONTO) / NÃO (0 PONTO) \\
\hline APOIO PARA OS PÉS & SIM (1 PONTO) / NÃO (0 PONTO) \\
\hline AVALIAÇÃO DO TECLADO & SIM (1 PONTO) / NÃO (0 PONTO) \\
\hline AVALIAÇÃO DO MONITOR & SIM (1 PONTO) / NÃO (0 PONTO) \\
\hline AVALIAÇÃO DO GABINETE & SIM (0 PONTO) / NÃO (1 PONTO) \\
\hline AVALIAÇÃO GERAL & SIM (1 PONTO) / NÃO (0 PONTO) \\
\hline
\end{tabular}


Tabela 2 - Critério de avaliação dos questionários

Fonte: SlideShare (2014)

\begin{tabular}{|l|l|}
\hline 91\% A 100\% DOS PONTOS & $\begin{array}{l}\text { CONDIÇÃO ERGONOMICA } \\
\text { EXCELENE }\end{array}$ \\
\hline $71 \%$ A 90\% DOS PONTOS & BOA CONDIÇÃO ERGONOMICA \\
\hline $51 \%$ A 70\% DOS PONTOS & $\begin{array}{l}\text { CONDIÇÃO ERGONOMICA } \\
\text { RAZOAVEL }\end{array}$ \\
\hline $31 \%$ A 50\% DOS PONTOS & CONDIÇÃO ERGONOMICA RUIM \\
\hline $\begin{array}{l}\text { MENOS QUE 31\% DOS } \\
\text { PONTOS }\end{array}$ & $\begin{array}{l}\text { CONDIÇÃO ERGONOMICA } \\
\text { PÉSSIMA }\end{array}$ \\
\hline
\end{tabular}

Tabela 3 - Critério de interpretação dos itens

Fonte:SlideShare (2014)

- Recurso Humano

Analista de RH: Profissional responsável por atuar com a área de recrutamento e seleção, com convocação de candidatos, entrevistas individuais e coletivas, além da graduação é essencial que possua conhecimentos abrangentes na área de seleção, testes psicológicos e visão sistêmica em recursos humanos (InfoJobs). Atividades realizadas: 90\% na posição sentada e $10 \%$ na posição em pé. Funcionário entrevistado trata-se do Edinaldo Maria da Paula, tempo de empresa 3 meses (Figura 1).

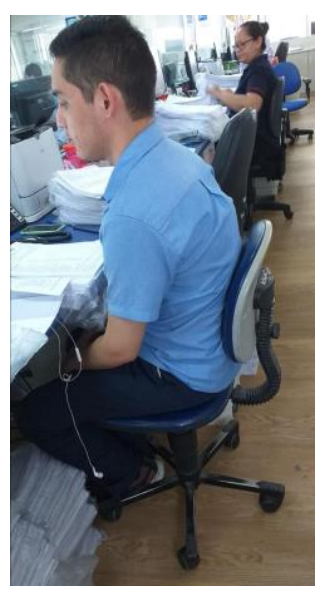

Figura 1

Edinaldo-Analista RH

Auxiliar de RH: Ajuda a realizar os processos de todo o departamento de pessoal, que abrangem desde o controle de frequência dos funcionários e cálculo da folha de pagamento, até o lançamento de dados em sistemas de gestão, coleta de assinaturas em holerites e outras rotinas pertinentes ao setor. Atividades realizadas: $90 \%$ na posição sentada e $10 \%$ na posição em pé. Funcionário entrevistado trata-se do Francisco Cavalcante, tempo de empresa três anos (Figura 2). 


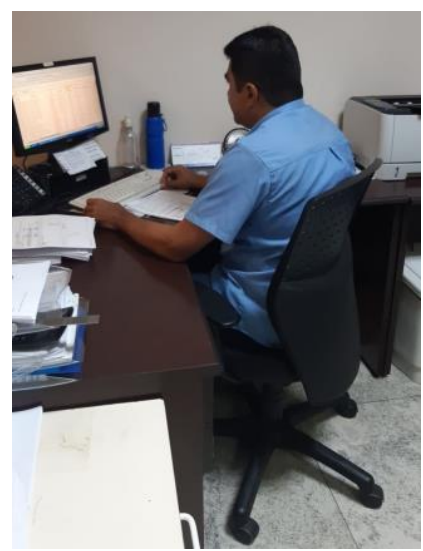

Figura 2

Francisco-Auxiliar RH

- Faturamento

Auxiliar de Faturamento: Analisa faturamento de contas médicas, como materiais, medicamentos, exames e honorários, confere contas de pacientes, acompanha recursos de glosas, realiza fechamento de guias e emite notas fiscais. Atividades realizadas: $100 \%$ na posição sentada, neste setor foram entrevistadas duas funcionárias sendo que as mesmas têm a mesma função. Funcionárias entrevistadas: Thalita Silva de Souza, tempo de empresa 13 anos (Figura 3) e Dayse Maciel Correa, tempo de empresa 7 anos (Figura 4).

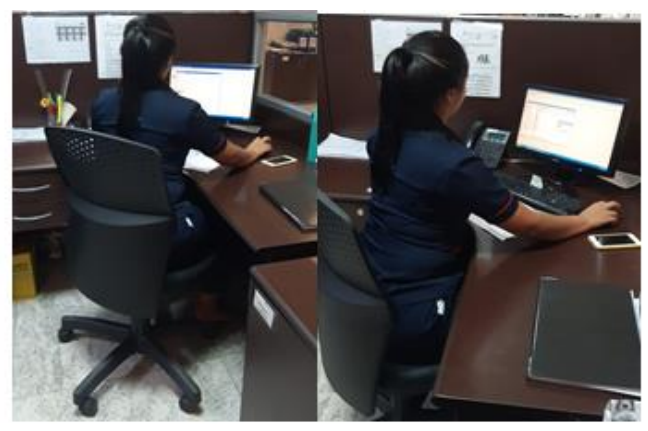

Figura 3

Thalita - Auxiliar de Faturamento

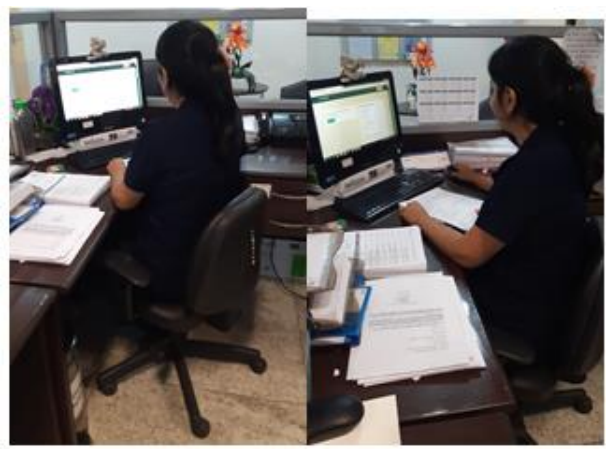

Figura 4

Dayse - Auxiliar de Faturamento

- Central de Autorização

Líder da Central de Autorização: Funcionário responsável pela liderança em equipe no atendimento pessoal e telefônico, dando suporte as analistas da central de autorização em processos eletivos (pacientes aguardam autorização dos processos cirúrgicos em casa), pacientes internados (pacientes internados nesta unidade hospitalar que o mesmo aguarda autorização do procedimento cirúrgico) e pós-cirúrgicos (procedimentos cirúrgicos já realizados porem sem autorização prévia) que estão demorando a ser finalizado dentro do prazo estipulado pela ANS (21 dias uteis) tratando os mesmos com convenio e fornecedores. Atividades realizadas: $100 \%$ na posição sentada. Funcionária entrevistada 
trata-se da Priscila dos Santos, tempo de empresa 10 anos (Figura 5).

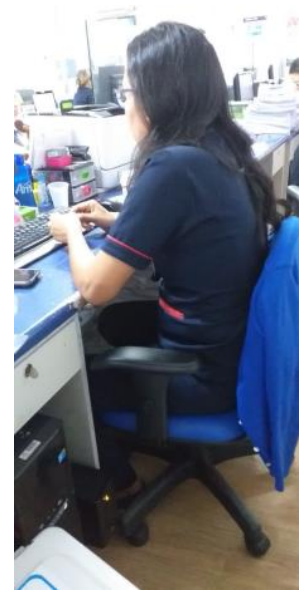

Figura 5

Priscila - Líder Central Autorização

Coordenadora da Central de Autorização: Orienta sobre as normas e sistemas de trabalho, discutindo periodicamente com a equipe de trabalho, aplicando a revisão das rotinas, análise de desempenho de cada analista da central de autorização semanalmente. Atividades realizadas: $100 \%$ na posição sentada. Funcionária entrevistada trata-se da Marilza Mota, tempo de empresa 3 anos (Figura 6).

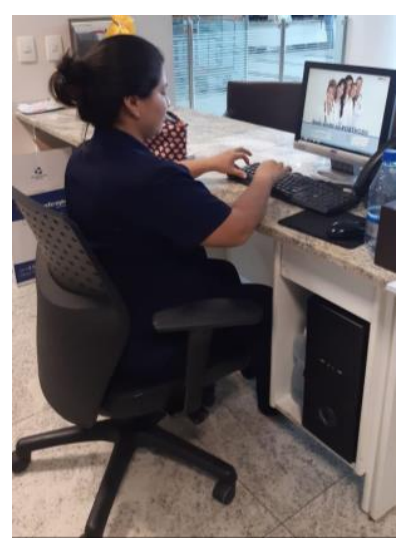

Figura 6

Marilza- Coordenadora da Central de Autorização

- $\quad$ Envio de Contas Médicas

Auxiliar de faturamento: Realiza o lançamento de informações de prontuários e auxilia na análise de contas médicas, glosas, folha de pagamento de credenciados para assegurar o correto faturamento e envio ao convênio. Atividades realizadas: $90 \%$ na posição sentada e $10 \%$ na posição em pé, neste setor foram entrevistadas duas funcionárias sendo que as mesmas têm a mesma função. Funcionárias entrevistadas: Jomara Fontella, tempo de empresa 13 anos (Figura 7) e Priscila Franco da Gama, tempo de empresa 5 anos (Figura 8). 


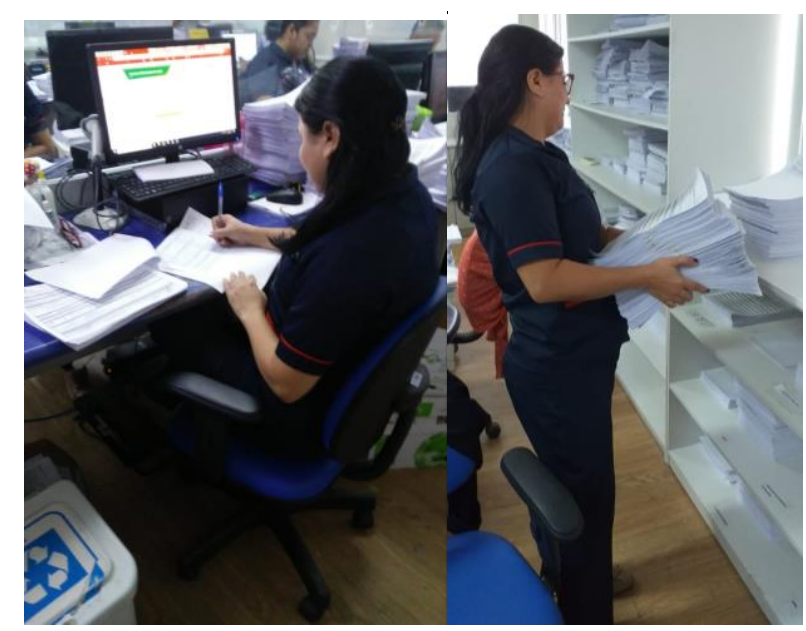

Figura 7

Jomara- Auxiliar de Faturamento (Contas Médicas)

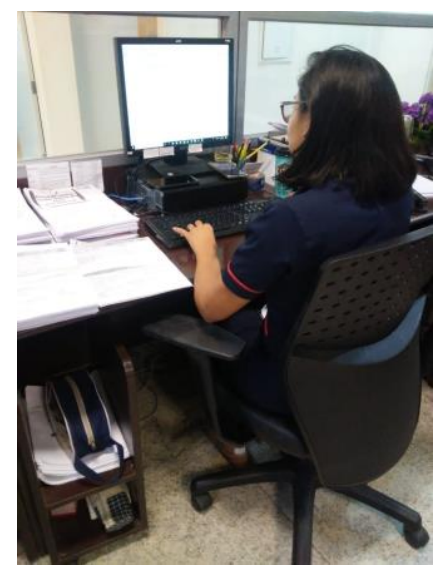

Figura 8

Priscila- Auxiliar de Faturamento (Contas Médicas)

\subsection{Discussão dos Resultados}

Avaliando resultado de cada funcionário temos:

- $\quad$ Analista de RH: Edinaldo

\begin{tabular}{|l|l|l|}
\hline ITEM PESQUISADO & PONTOS & AVALIAÇÃO \\
\hline AVALIAÇÃO DA CADEIRA & $86,7 \%$ dos pontos & Boa condição ergonômica \\
\hline MESA DE TRABALHO & $80 \%$ dos pontos & Boa condição ergonômica \\
\hline APOIO PARA OS PÉS & $0 \%$ dos pontos & Condição ergonômica péssima \\
\hline AVALIAÇÃO DO TECLADO & $80 \%$ dos pontos & Boa condição ergonômica \\
\hline AVALIACAO DO MONITOR & $100 \%$ dos pontos & Condição ergonômica excelente \\
\hline & & \\
AVALIACAO DO GABINETE & $100 \%$ dos pontos & Condição ergonômica excelente \\
\hline AVALIACAO GERAL & $75 \%$ dos pontos & Boa condição ergonômica \\
\hline
\end{tabular}

Tabela 4- Resultado Check List funcionário RH

Requer uma atenção na falta de suporte de altura para o monitor, ficar um pouco mais em pé, pois a permanência do tempo sentado é maior, não possui apoio para os pés. Grau risco- Bom para a atividade realizada. 
- Auxiliar de RH: Francisco

\begin{tabular}{|l|l|l|}
\hline \multicolumn{1}{|c|}{ ITEM PESQUISADO } & PONTOS & AVALIAÇÃO \\
\hline AVALIAÇÃO DA CADEIRA & $66,7 \%$ dos pontos & Condição ergonômica razoável \\
\hline MESA DE TRABALHO & $100 \%$ dos pontos & Condição ergonômica excelente \\
\hline APOIO PARA OS PÉS & $100 \%$ dos pontos & Condição ergonômica excelente \\
\hline AVALIAÇÃO DO TECLADO & $40 \%$ dos pontos & Condição ergonômica ruim \\
\hline AVALIACAO DO MONITOR & $100 \%$ dos pontos & Condição ergonômica excelente \\
\hline & $66,7 \%$ dos pontos & Condiçãa ergonômica razoável \\
\hline AVALIACAO DO GABINETE & $100 \%$ dos pontos & Condição ergonômica excelente \\
\hline AVALIACAO GERAL &
\end{tabular}

Tabela 5- Resultado Check List funcionário RH

Requer uma atenção na falta de suporte de altura para o monitor, ficar um pouco mais em pé, pois a permanência do tempo sentado é maior, cadeira não é adequada ergonomicamente tendo o encosto duro, não ajustável, rodízios duros, gabinete toma espaço no posto de trabalho. Grau risco-Moderado para atividade.

- Auxiliar de faturamento: Thalita

\begin{tabular}{|l|l|l|}
\hline ITEM PESQUISADO & PONTOS & AVALIAÇÃO \\
\hline AVALIAÇÃO DA CADEIRA & $40 \%$ dos pontos & Condição ergonômica ruim \\
\hline MESA DE TRABALHO & $80 \%$ dos pontos & Boa condição ergonômica \\
\hline APOIO PARA OS PÉS & $0 \%$ dos pontos & Condição ergonômica péssima \\
\hline AVALIAÇÃO DO TECLADO & $100 \%$ dos pontos & Condição ergonômica excelente \\
\hline AVALIACAO DO MONITOR & $60 \%$ dos pontos & Condição ergonômica razoável \\
\hline AVALIACAO DO GABINETE & $100 \%$ dos pontos & Condição ergonômica excelente \\
\hline AVALIACAO GERAL & $50 \%$ dos pontos & Condição ergonômica ruim \\
\hline
\end{tabular}

Tabela 6- Resultado Check List funcionário auxiliar faturamento

Requer uma atenção na falta de suporte de altura para o monitor, ficar um pouco mais em pé, pois a funcionária permanece sua jornada toda sentada, cadeira não é adequada ergonomicamente tendo o encosto duro, não ajustável, rodízios duros, não possui apoio para os pés. Grau risco- Ruim para a atividade

- Auxiliar de faturamento: Dayse

\begin{tabular}{|l|l|l|}
\hline ITEM PESQUISADO & PONTOS & AVALIAÇÃO \\
\hline AVALIAÇÃO DA CADEIRA & $60 \%$ dos pontos & Condição ergonômica razoável \\
\hline MESA DE TRABALHO & $80 \%$ dos pontos & Boa condição ergonômica \\
\hline APOIO PARA OS PÉS & $0 \%$ dos pontos & Condição ergonômica péssima \\
\hline AVALIAÇÃO DO TECLADO & $40 \%$ dos pontos & Condição ergonômica ruim \\
\hline AVALIACAO DO MONITOR & $80 \%$ dos pontos & Boa condição ergonômica \\
\hline AVALIACAO DO GABINETE & $100 \%$ dos pontos & Condiçã ergonômica excelente \\
\hline AVALIACAO GERAL & $75 \%$ dos pontos & Boa condição ergonômica \\
\hline
\end{tabular}

Tabela 7- Resultado Check List funcionário auxiliar faturamento

Requer uma atenção na falta de suporte de altura para o monitor, ficar um pouco mais em pé, pois a funcionária permanece sua jornada toda sentada, cadeira não é adequada ergonomicamente tendo o encosto duro, não ajustável, rodízios duros, não possui apoio para os pés, teclado inadequado ergonomicamente. Grau risco- Moderado para a 
atividade.

- $\quad$ Líder da Central de Autorização: Priscila

\begin{tabular}{|l|l|l|}
\hline ITEM PESQUISADO & PONTOS & AVALIAÇÃO \\
\hline AVALIAÇÃO DA CADEIRA & $100 \%$ dos pontos & Condição ergonômica excelente \\
\hline MESA DE TRABALHO & $60 \%$ dos pontos & Condição ergonômica razoável \\
\hline APOIO PARA OS PÉS & $83,3 \%$ dos pontos & Boa condição ergonômica \\
\hline AVALIAÇÃO DO TECLADO & $80 \%$ dos pontos & Boa condição ergonômica \\
\hline AVALIACAO DO MONITOR & $100 \%$ dos pontos & Condição ergonômica excelente \\
\hline AVALIACAO DO GABINETE & $66,7 \%$ dos pontos & Condição ergonômica razoável \\
\hline AVALIACAO GERAL & $100 \%$ dos pontos & Condição ergonômica excelente \\
\hline
\end{tabular}

Tabela 8- Resultado Check List funcionário líder central autorização

Requer uma atenção na falta de suporte de altura para o monitor, ficar um pouco mais em pé, pois a funcionária permanece sua jornada toda sentada, postura ao falar no telefone incorreta, pois a mesma fica com o encostado entre sua bochecha e ombro, gabinete toma espaço no posto de trabalho. Grau risco- Ótimo para a atividade.

- Coordenadora da Central de Autorização: Marilza

\begin{tabular}{|l|l|l|}
\hline ITEM PESQUISADO & PONTOS & AVALIAÇÃO \\
\hline AVALIAÇÃO DA CADEIRA & $100 \%$ dos pontos & Condição ergonômica excelente \\
\hline MESA DE TRABALHO & $100 \%$ dos pontos & Condição ergonômica excelente \\
\hline APOIO PARA OS PÉS & $66,7 \%$ dos pontos & Condição ergonômica razoável \\
\hline AVALIAÇÃO DO TECLADO & $80 \%$ dos pontos & Boa condição ergonômica \\
\hline AVALIACAO DO MONITOR & $80 \%$ dos pontos & Boa condição ergonômica \\
\hline AVALIACAO DO GABINETE & $100 \%$ dos pontos & Condição ergonômica excelente \\
\hline AVALIACAO GERAL & $75 \%$ dos pontos & Boa condição ergonômica \\
\hline
\end{tabular}

Tabela 9- Resultado Check List funcionário líder central autorização

Requer uma atenção na falta de suporte de altura para o monitor, ficar um pouco mais em pé, pois a funcionária permanece sua jornada toda sentada, postura ao falar no telefone incorreta, pois a mesma fica com o encostado entre sua bochecha e ombro, cadeira não é adequada ergonomicamente tendo o encosto duro, não ajustável, rodízios duros. Grau risco- Ótimo para a atividade

- $\quad$ Auxiliar de faturamento (Envio de contas médicas): Jomara

\begin{tabular}{|l|l|l|}
\hline ITEM PESQUISADO & PONTOS & AVALIAÇÃO \\
\hline AVALIAÇÃO DA CADEIRA & $73,3 \%$ dos pontos & Boa condição ergonômica \\
\hline MESA DE TRABALHO & $60 \%$ dos pontos & Condição ergonômica razoável \\
\hline APOIO PARA OS PÉS & $50 \%$ dos pontos & Condição ergonômica ruim \\
\hline AVALIAÇÃO DO TECLADO & $40 \%$ dos pontos & Condição ergonômica ruim \\
\hline AVALIACAO DO MONITOR & $80 \%$ dos pontos & Boa condição ergonômica \\
\hline AVALIACAO DO GABINETE & $0 \%$ dos pontos & Condição ergonômica péssima \\
\hline AVALIACAO GERAL & $75 \%$ dos pontos & Boa condição ergonômica \\
\hline
\end{tabular}

Tabela 10- Resultado Check List funcionário auxiliar contas médicas

Teclado não apropriado ergonomicamente, apoio para os pés inadequado, gabinete toma espaço no posto de trabalho e transmite calor. Grau risco- Péssimo para a atividade.

- $\quad$ Auxiliar de faturamento (Envio de contas médicas): Priscila

\begin{tabular}{|l|l|l|}
\hline ITEM PESQUISADO & PONTOS & AVALIAÇÃO \\
\hline AVALIAÇÃO DA CADEIRA & $86,7 \%$ dos pontos & Boa condição ergonômica \\
\hline MESA DE TRABALHO & $40 \%$ dos pontos & Condição ergonômica ruim \\
\hline APOIO PARA OS PÉS & $0 \%$ dos pontos & Condição ergonômica péssima \\
\hline AVALIAÇÃO DO TECLADO & $40 \%$ dos pontos & Condição ergonômica ruim \\
\hline AVALIACAO DO MONITOR & $80 \%$ dos pontos & Boa condição ergonômica \\
\hline & $66,7 \%$ dos pontos & Condição ergonômica razoável \\
\hline
\end{tabular}




\begin{tabular}{|l|l|l|}
\hline AVALIACAO DO GABINETE & & \\
\hline AVALIACAO GERAL & $75 \%$ dos pontos & Boa condição ergonômica \\
\hline
\end{tabular}

Mesa de trabalho em péssimo estado, apoiador para os pés ruins, teclado inapropriado ergonomicamente, cadeira não é adequada ergonomicamente tendo o encosto duro, não ajustável, rodízios duros Grau risco- Moderada para a atividade.

Para ser feito um comparativo de cada item pesquisado, será apresentada através de gráfico a avaliação dos setores:

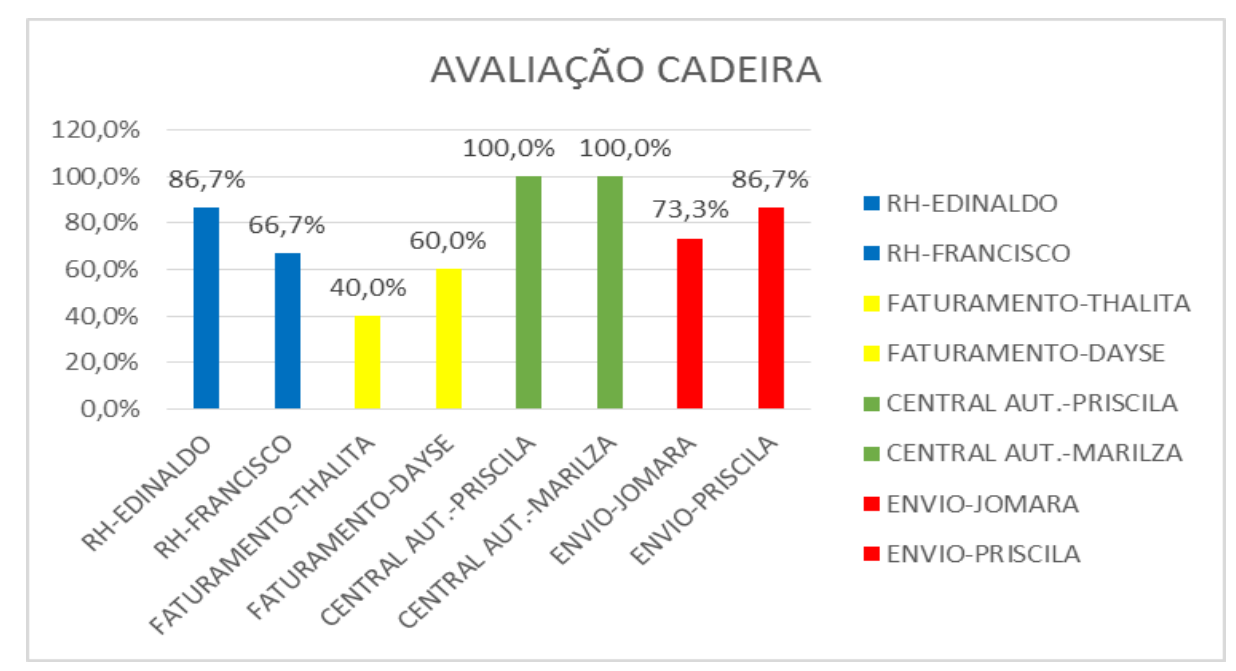

Figura 9- Avaliação cadeira

Com a figura 9 avaliando pode-se concluir que o setor com melhores condicoes ergonomicas com relacao a avaliçao da cadeira a central de autorizacao com $100 \%$, tendo os demais com a condição mediana e o setor de faturamento que requer maior atenção pois foi o que obteve o pior rendimento.

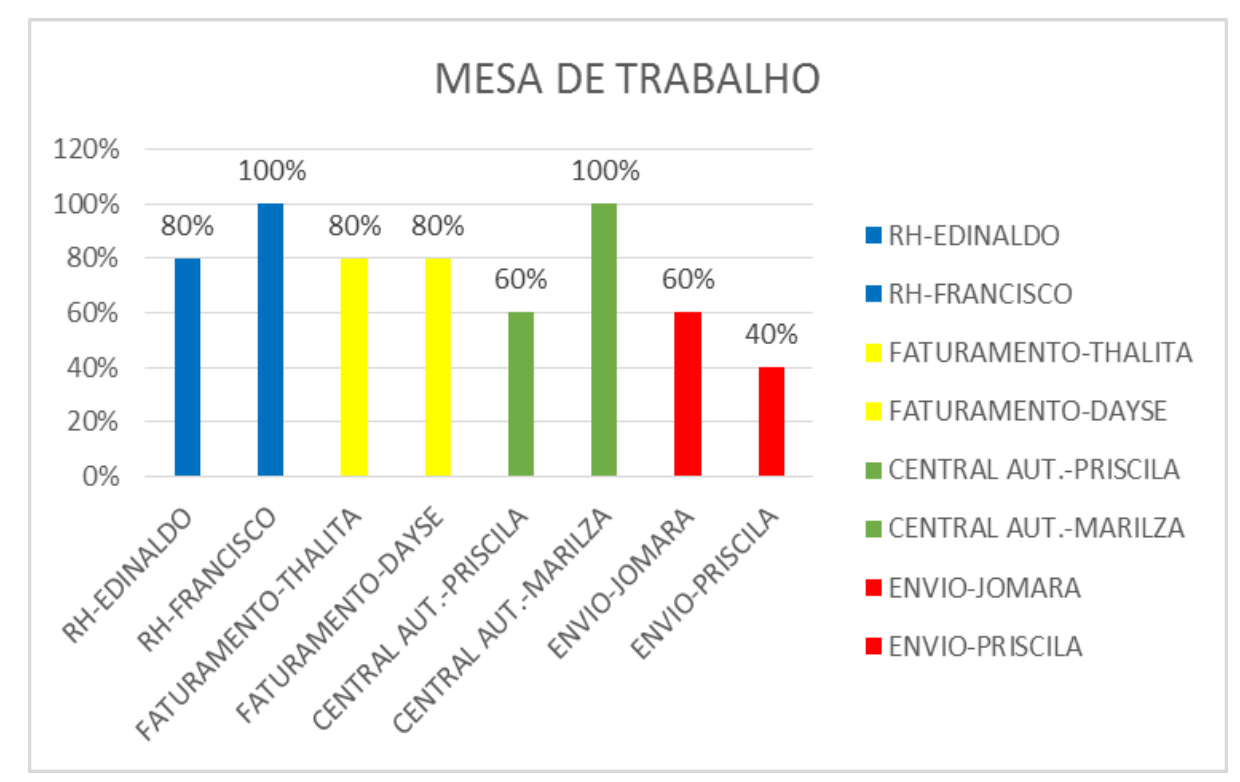

Figura 10- Mesa de trabalho 
O item mesa de trabalho conforme analisado no gráfico da figura 10,o setor mais crítico é o envio de contas médicas com porcentagem (60\% e 40\%) e o setor com melhor avaliação ergonomica a central de autorização (60\% e 100\%).

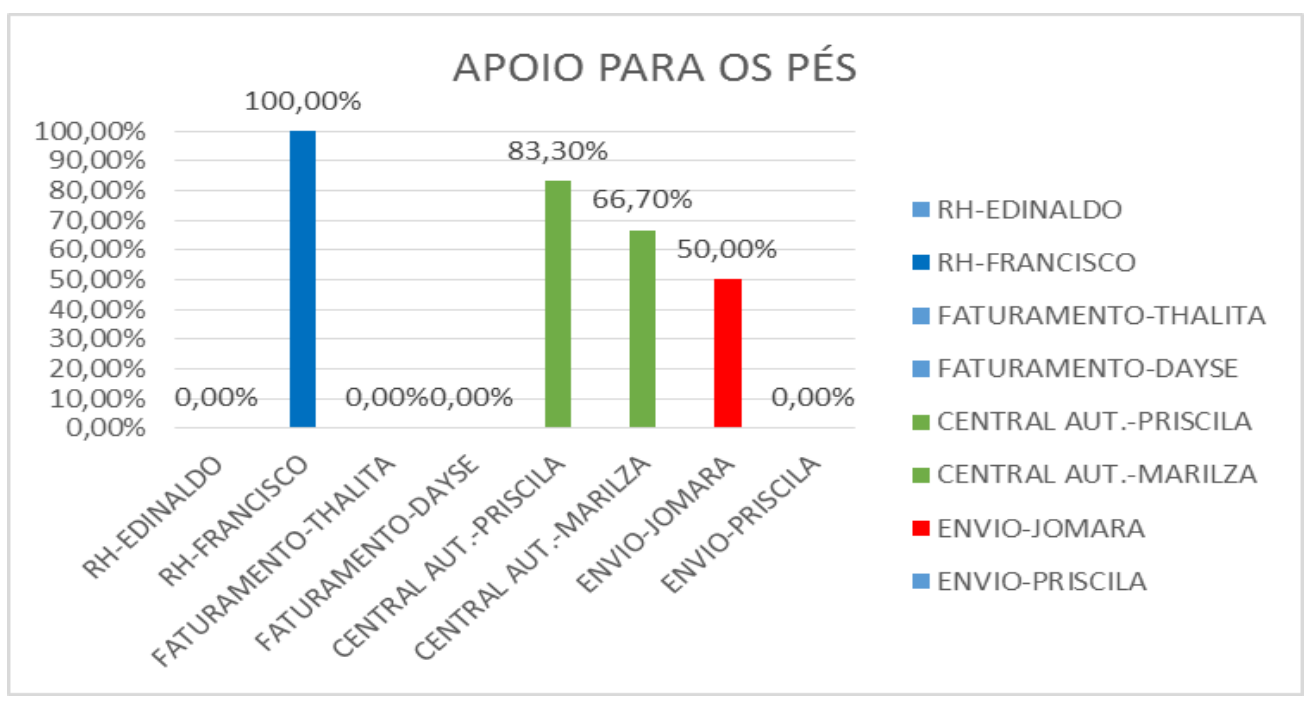

Figura 11- Apoio para os pés

Na figura 11 que representa o item apoio para os pés é o considerado mais preocupante pois em muitos setores não foram encontrados a presença do mesmo, e os colaboradores que possuem os mesmos não são apropriados ergonomicamente.

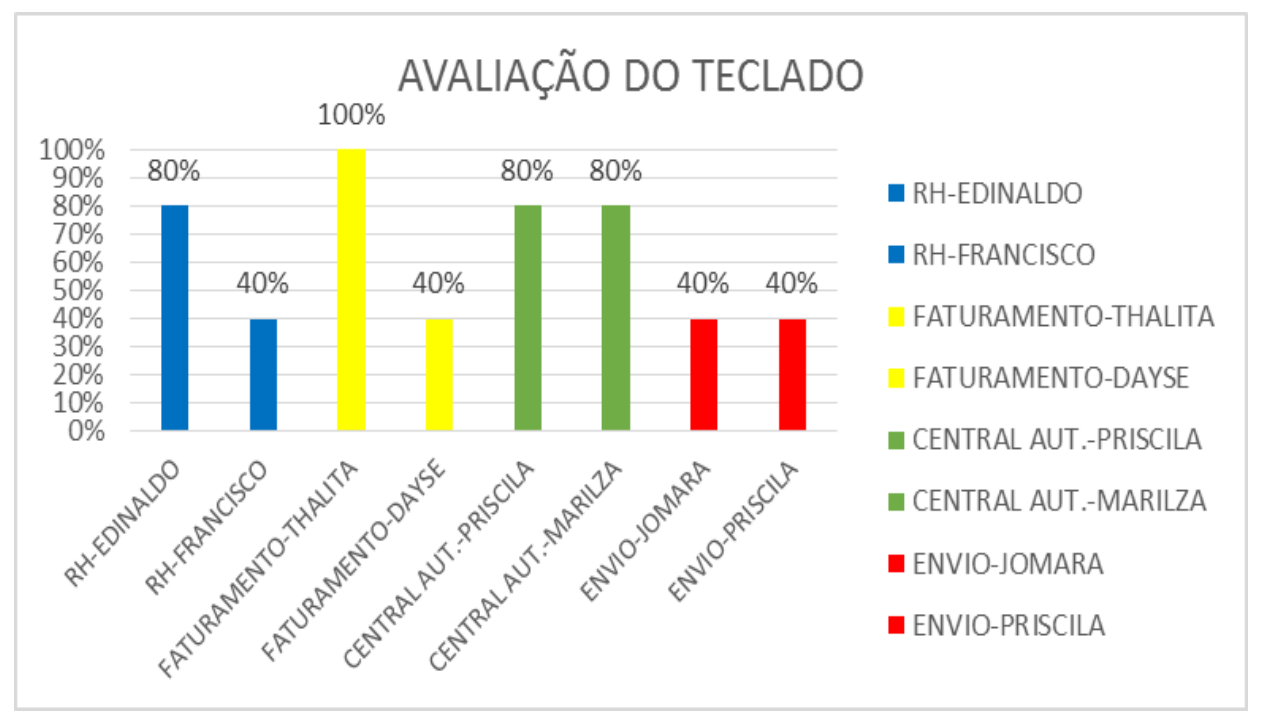

Figura 12- Avaliação do teclado

Com a avaliação do teclado, representado na figura 12 , foi obtido um valor mínimo de 40\% em 3 setores sendo eles: RH, Faturamento e Envio de contas médicas os considerados mais críticos. 


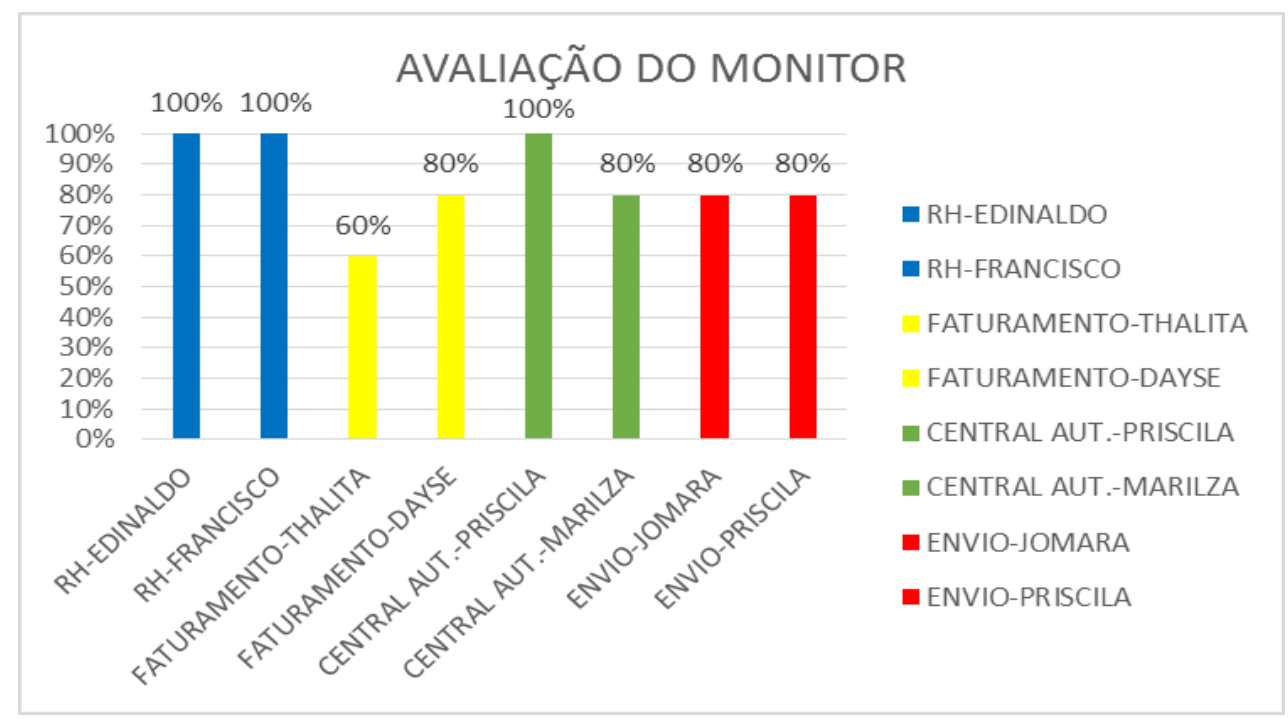

Figura 13- Avaliação do monitor

$\mathrm{Na}$ avaliação do monitor, através do gráfico da figura 13 o setor que melhor se destaca é o RH com $100 \%$ avaliado com uma ótima condição ergonômica, porém ainda temos muitos colaboradores que estao sem nenhum suporte para o monitor.

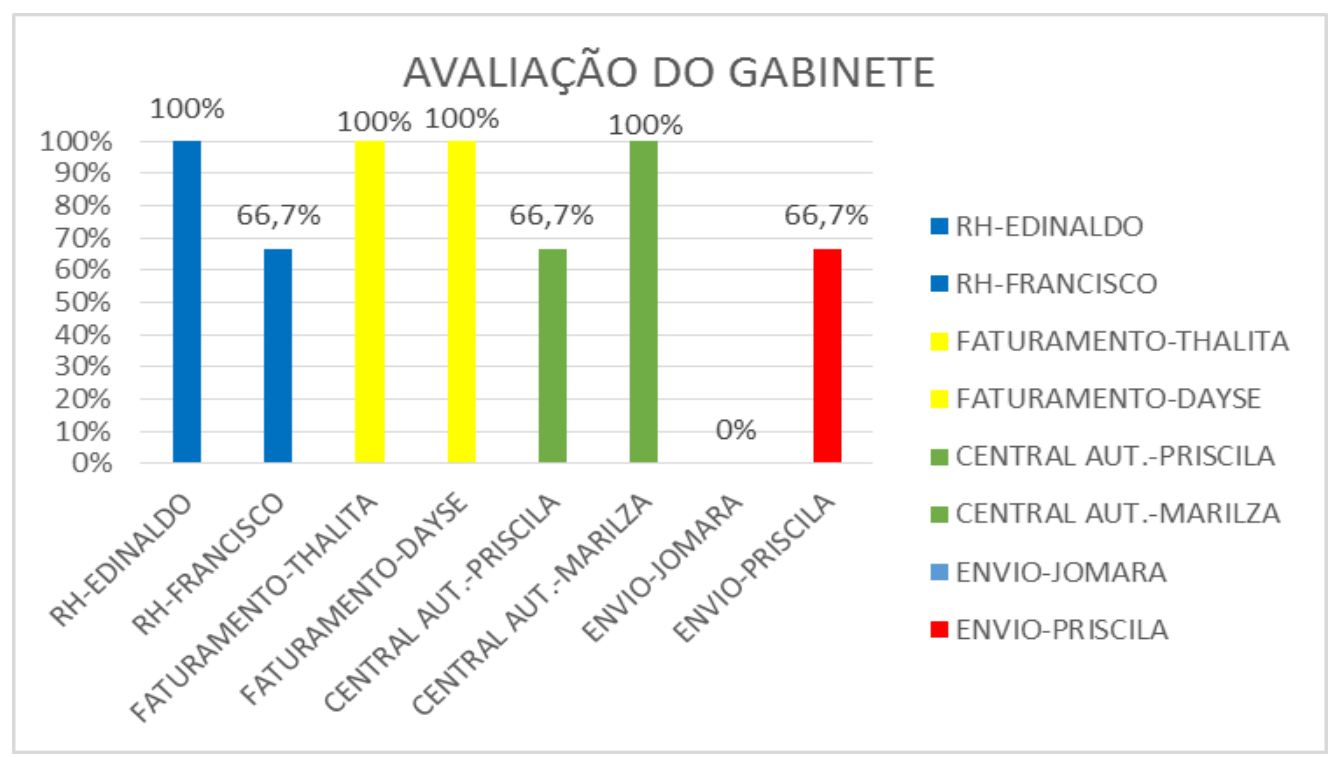

Figura 14- Avaliação do monitor

$\mathrm{Na}$ avaliação do gabinete, representado no grafico acima, o setor do faturamento sendo o melhor ergonomicamente com $100 \%$, porém o mais preocupante é o setor do envio de contas médicas, pois nele tem como resultado de avaliação a menores $0 \%$ e 66,7\%. 


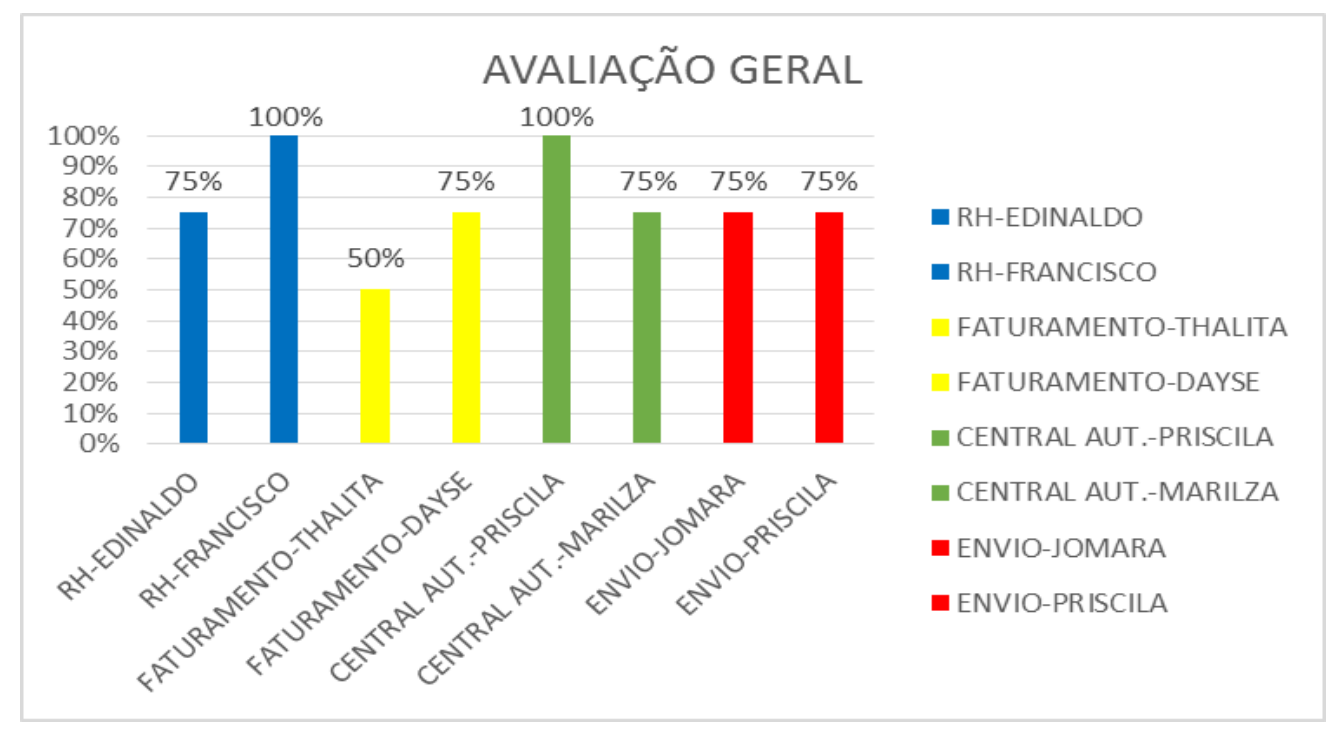

Figura 15- Avaliação geral

Com a avaliação geral, representada pela figura 15, o hospital possui setores que possuem pouco espaço para desenvolver as atividades, 100\% dos colaboradores almejam a implantação de um projeto ergonômico voltado para a área administrativa e das práticas de exercicios laborais.

Aparentemente os fatores relacionados ao layout e mobiliário que constatamos por meio de visitas técnicas, fotografias, depoimentos que foram validados, fazem com que os colaboradores trabalhem com posturas forçadas. No setor do envio de contas médicas: estão trabalhando com excesso de carregamento de pesos, Layout inadequado, trazendo assim conseqüências para a saúde dos colaboradores vale ressaltar que todos que realizaram o questionário relataram que sentem dores por questões ergonômicas no final da sua jornada de trabalho.

\subsection{Plano de Ação}

a) Melhorias Ergonômicas:

- Armazenar os blocos de papel em bancada onde o colaborador não realize flexão de tronco.

- Disponibilizar carrinho próprio do setor.

- Disponibilizar um local de arquivamento de blocos mais próximo, não tão alto e mais amplo

- Realizar treinamento abordando sobre o manuseio manual de carga.

- Realizar palestras/treinamento abordando quanto à melhor postura a ser adotada pelo colaborador.

- Realizar exercícios específicos de cinesioterapia laboral/ ginástica laboral para melhorar o desempenho

- Cadeiras adequadas conforme normas ergonômicas 
- $\quad$ Suporte para altura do monitor

- $\quad$ Suporte para os pés

- $\quad$ Suporte para mouse

- Teclados novos

- Head Set para setores que utilizam com maior frequiência o telefone sendo eles o setor central de autorização

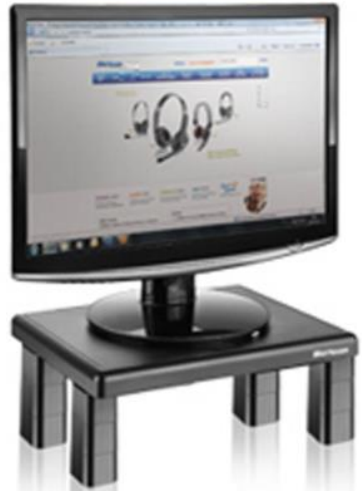

Figura 16 Suporte para monitor

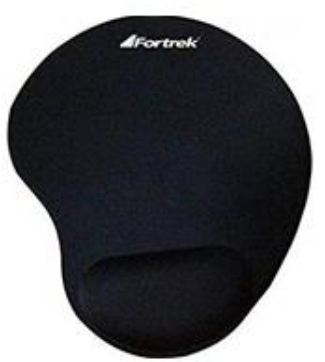

Figura 18 Mouse Pad em gel

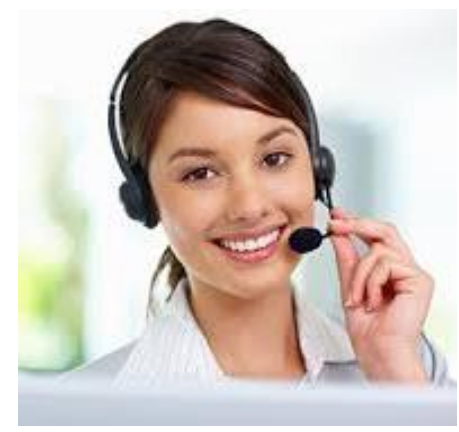

Figura 17 Head Set

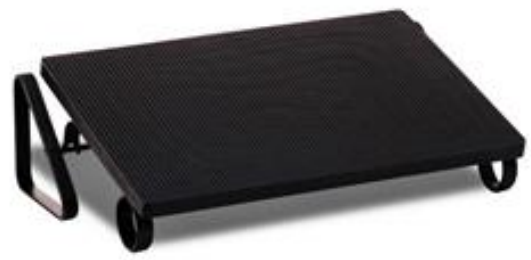

Figura 19 Suporte para os pés 


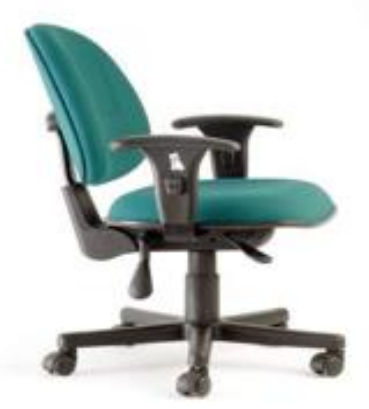

Figura 20

Cadeiras ajustáveis e confortáveis

b) Tipos de Alongamento (SINTRAJUFE RS-2018):

Mantenha a posição máxima de alongamento por dez segundos, repetindo os exercícios duas ou três vezes para ambos os lados, fazendo por dez minutos sendo nas pausas, antes e após a jornada de trabalho, alguns tipos de alongamento ilustrado na figura 21 .
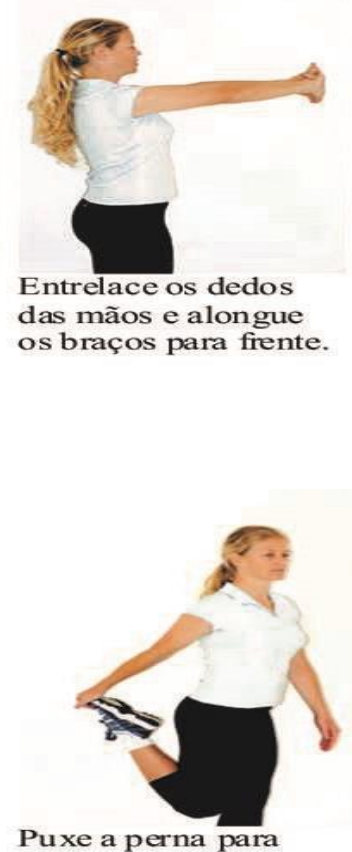

Puxe a perna para trás, segurando a ponta do pé. Repita o exercício na outra perna.
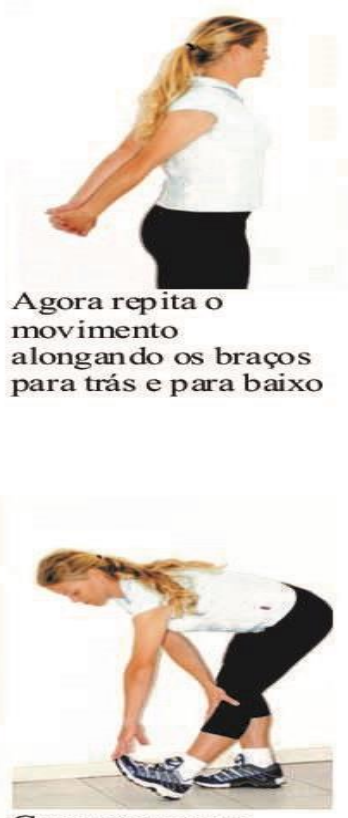

Com uma perna esticada a frente, incline o tronco para baixo, tentando encostar a mão na ponta do pé. A outra perna permanece levemente flexionada. Repita o exercício na outra perna.

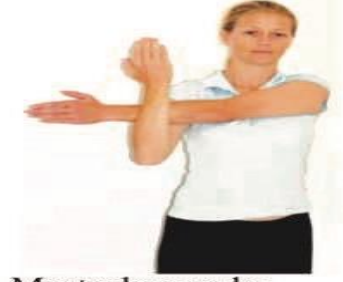

Mantenha um dos

braços esticados para o lado oposto. Alongue-o com a ajuda do outro

braço. Repita o

exercício no outro braço
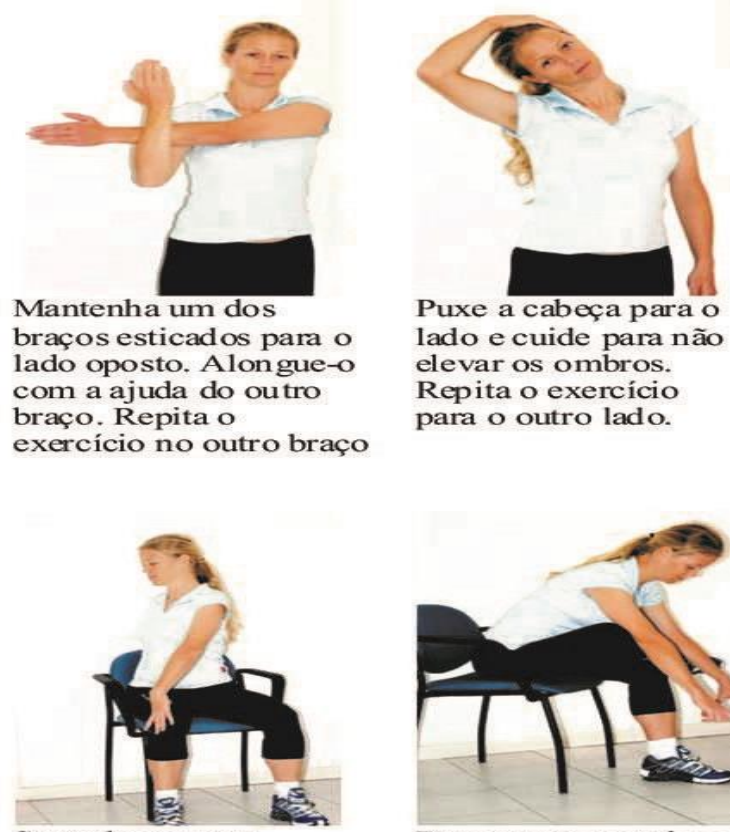

Sentado em uma cadeira, gire o tronco para um dos lados e olhe para trás. Repita o exercício para o outro lado.

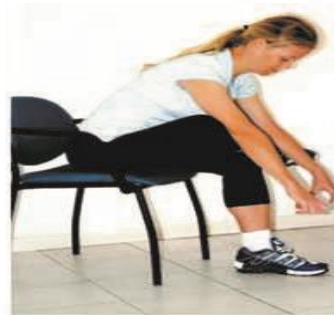

Permaneça sentado e dobre uma perna em cima da outra. Em seguida, incline o corpo para baixo e deixe os braços soltos. 


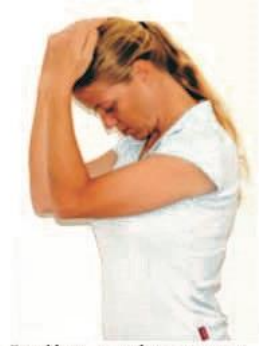

Incline a cabeça para baixo e segure-a com as duas mãos.

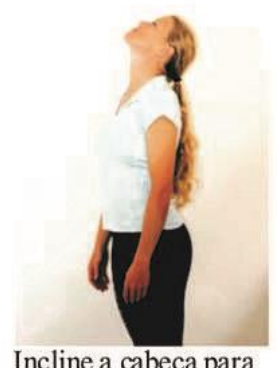

Incline a cabeça para trás, mantendo a boca fechada e o pescoço esticado.

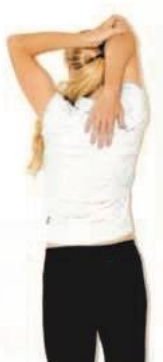

Com uma das mãos, segure o cotovelo oposto e empurre-o em direção ao meio das costas. Repita o exercício no outro braço.

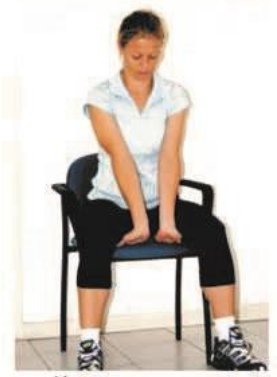

Apóie as mãos numa cadeira e mantenha os braços esticados.

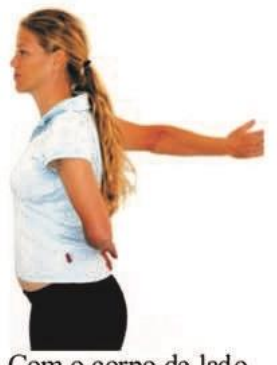

Com o corpo de lado para uma parede, estique os braços para trás, mantendo na altura do ombro.

Repita o exercício no outro braço.

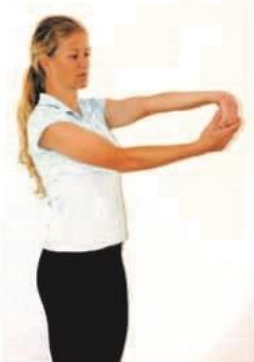

Estique o braço para frente e dobre o punho para baixo, com a mão virada para fora. Pressione levemente todos os dedos, até sentir o braço alongar.repita o exercício coma mão virada para dentro. Faça nos dois braços.

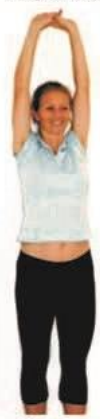

Para finalizar, entrelace os dedos e, na ponta dos pés, estique os braços para cima.

pema de baixo

levemente flexionada $\mathrm{e}$ a de cima esticada.

Leve os braço em

direção da ponta do pé.

Repita o exercício com

as pernas invertidas.

Figura 21- Alguns tipos de alongamento

Fonte: Sintrajufe (2018)

c) Melhor Postura Adotada (ARINA ARAUJO-2014)

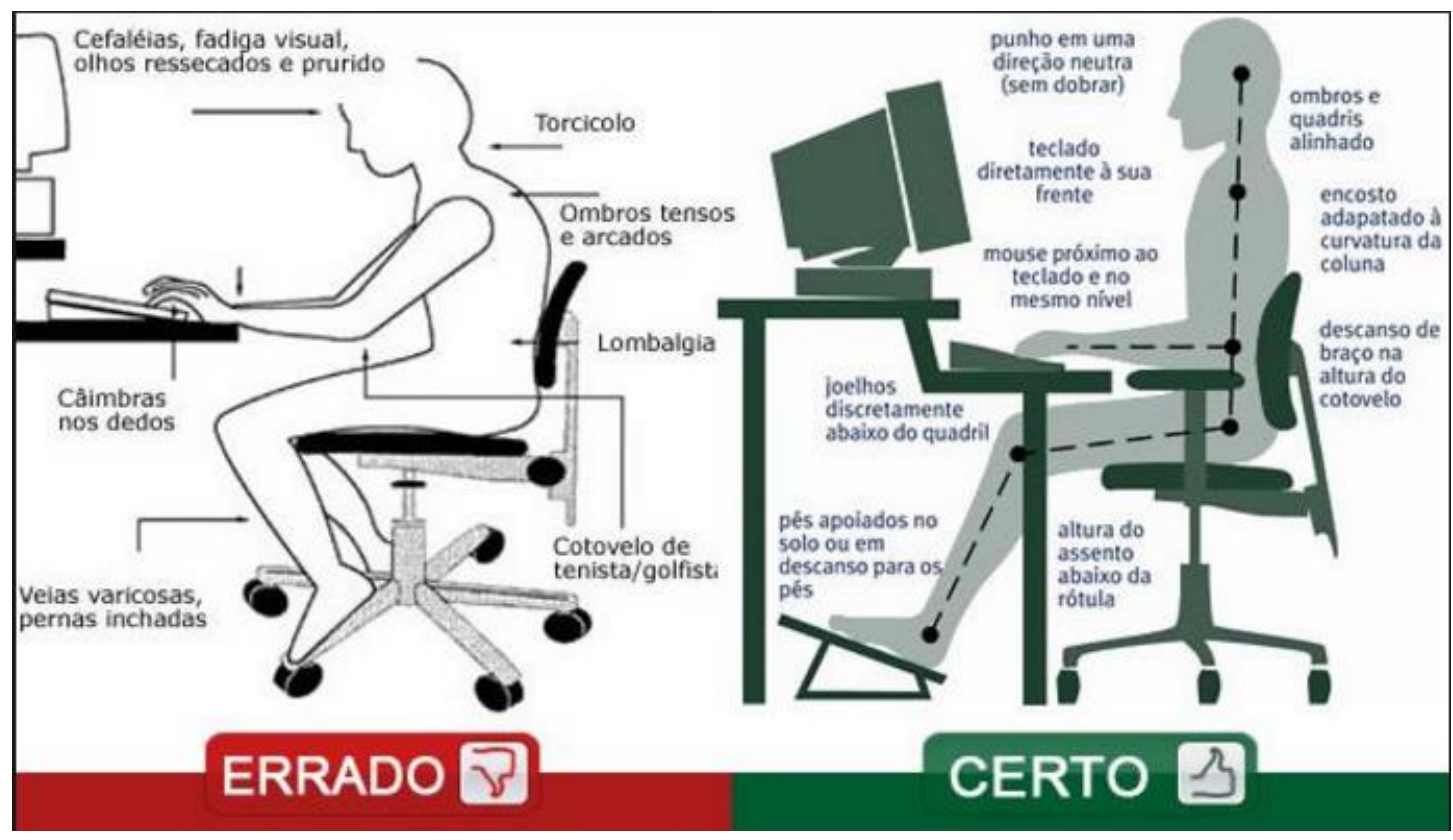

Figura 22- Comparativo de postura ao se sentar 
- Altura e estrutura do assento: o assento deve ser liso, levemente inclinado para trás e facilmente ajustável, para que a altura atenda perfeitamente ao utilizador da cadeira (WorkSolution-2019)

- Largura e profundidade do assento: uma cadeira ergonômica deve ter profundidade e largura suficientes para suportar o utilizador com todo o conforto possível (WorkSolution-2019)

- $\quad$ Suporte lombar: é importante que o encosto ou suporte permita o encaixe das costas com proteção da coluna, exigindo menos esforço da cervical para manter-se em boa postura (WorkSolution-2019)

- Apoio de trás: o apoio traseiro (encosto da cadeira) deve ser ajustável, tanto para frente quanto para trás (WorkSolution-2019)

- Material do assento: o material do assento e do encosto deve ser acolchoado para manter o conforto mesmo em períodos extensos de trabalho (WorkSolution-2019)

- Apoio dos braços: quando a cadeira ergonômica possuir apoio para os braços, estes também devem ser ajustáveis (WorkSolution-2019)

- Rodízios: a cadeira ergonômica deve rodar facilmente, sem esforços, não importando o tipo de piso (WorkSolution-2019)

- Estabilidade: ambientes de trabalho precisam de cadeiras ergonômicas de boa estabilidade, para suportar o dia a dia do ambiente laboral. Para isto, uma base contendo cinco pontos (ou cinco estrelas) é recomendável (WorkSolution-2019)

- Selos e certificados de qualidade: um produto que segue as normas de ergonomia ABNT, geralmente traz na embalagem um selo de conformidade (WorkSolution-2019)

- Apoio para os pés: Para evitar tais complicações no ambiente de trabalho, foram desenvolvidas várias medidas ergonômicas capazes de preservar a coluna, o pescoço e os membros inferiores e superiores. Uma destas medidas ergonômicas é o uso de apoio para os pés no trabalho. (Blog Segurança do Trabalho-2019)

\subsection{Considerações Finais}

A ergonomia que tem como objetivo maior "ajudar" a tornar a humanidade mais feliz, passando a ter um papel importante neste processo, por isto é necessário conhece-la a fundo e aplicar seus métodos e técnicas de forma efetiva. Pretende-se estar contribuindo a formação de um senso crítico quanto ao tema, evidenciando sua importância e aplicação, inicialmente às atividades de trabalho e estendido à todas as esferas da vida.

Portanto, este projeto teve como objetivo fornecer os elementos necessários para o entendimento dos conceitos básicos da ergonomia, apresentando que já é a hora de ser preocupar com a saúde e bem-estar dos colaboradores do setor administrativo desta unidade de saúde, pois foi verificado a ausência da aplicação das técnicas de adaptação dos elementos ergonômicos neste ambiente hospitalar, nunca houve nenhum projeto ergonômico voltado para a área administrativa, sendo este um projeto piloto.

Analisado os resultados, foi mostrado como resultado o que pode ser implantado e melhorado, como por exemplo: realização diariamente de ginástica laboral, treinamento de melhor postura a ser adotada pelo colaborador, disponibilização do hospital para cada funcionário apoiador para os pés, suporte para o monitor. Logo com esta iniciativa pode aumentar os níveis de satisfação, eficácia, eficiência do trabalhador e assim diminuindo o índice de absenteísmo e o afastamento pelo INSS por motivos ergonômicos.

O estudo ergonômico deste projeto se faz necessário, não só pela exigência da Norma Regulamentadora número 17, mas como ferramenta complementar ao PPRA (Programa de Prevenção de Riscos Ambientais) e PCMSO (Programa de Controle Médico em Saúde Ocupacional). Tornando a empresa uma instituição protegida contra altos índices de doenças ocupacionais e queda de produtividade, consequente da falta de adaptações 
ergonômicas no ambiente de trabalho e manutenção técnica nesta área.

\subsection{Referências Bibliográficas}

- Hospital Santa Julia. Disponível:< http://www.hospitalsantajulia.com.br/>. Acesso em: 10 de setembro de 2019.

- ABERGO,O que é ergonomia. Disponível: $<$ http://www.abergo.org.br/internas.php?pg=o_que_e_ergonomia>. Acesso em $10 \mathrm{de}$ Setembro de 2019.

- NASCIMENTO, ALESSANDRA. Importância da Ergonomia. Disponível: <https://m.migalhas.com.br/depeso/241198/importancia-da-ergonomia $>$.Acesso em: 11 de setembro de 2019.

- SIGNIFICADOS. Significado de Ergonomia. Disponível: <https://www.significados.com.br/ergonomia/>. Acesso em: 11 de Setembro 2019.

- OLIVEIRA,ANA FLAVIA. Ergonomia: conceito, tipos e benefícios. Disponível: $<$ https://beecorp.com.br/blog/conheca-os-tipos-de-ergonomia/>. Acesso em:12 de Setembro de 2019.

- $\quad$ BETA EDUCAÇÃO. Ergonomia (NR-17): o que é e para que serve?.Disponivel:<https://betaeducacao.com.br/saiba-mais-sobre-a-nr17-ergonomia/>. Acesso em: 12 de Setembro de 2019.

- $\quad$ NR 17 - NORMA REGULAMENTADORA 17.

- Disponivel:<guiatrabalhista.com.br/legislacao/nr/nr17.htm>. Acesso em: 12 de Setembro de 2019.

- PINHEIRO,MONICA. Ergonomia Organizacional Disponivel:<http://www.sistemaambiente.net/Monica_Pinheiro/Monica_Pinheiro_Ergon omia_organizacional.htm>. Acesso em: 20 de Setembro de 2019.

- $\quad$ CRPG,CENTRO DE REABILITAÇÃO PROFISSIONAL DE GAIA. O que é Ergonomia.Disponivel:<http://www.crpg.pt/empresas/recursos/kitergonomia/Paginas/erg onomia.aspx >. Acesso em 17 de Setembro de 2019.

- $\quad$ SEGADAS,NATHALIA. Quais os objetivos da ergonomia. Disponivel:< https://www.trabalhosgratuitos.com/Exatas/Engenharia/QUAIS-OS-OBJETIVOS-DAERGONOMIA-1234008.html >. Acesso em 20 de Setembro de 2019.

- SINTRAJUFE. Projeto piloto de ginástica laboral tem início na Justiça do Trabalho de Porto Alegre. Disponivel:< https://www.sintrajufe.org.br/ultimas-noticiasdetalhe/16058/apos-solicitacao-do-sintrajufe-rs-projeto-piloto-de-ginastica-laboral-teminicio-na-justica-do-trabalho-de-porto-alegre>.Acesso em 17 de Setembro de 2019.

- AGUIAR,ANABEL.Checklist de Hudson Couto.Disponível:< https://pt.slideshare.net/anabelmaguiar/checklist-de-hudson-couto>.Acesso em 19 de Setembro de 2019.

- CARE,HEALTH.Analise Ergonomica do Trabalho.Disponível:< https://nucleohealthcare.com.br/blog/tag/aet/ >.Acesso em 19 de Setembro de 2019.

- $\quad$ COSTA.L.GOMES.Analise Ergonomica de Postos de Trabalho.Disponível:< http://www.crpg.pt/empresas/recursos/kitergonomia/Documents/EWA_Portugu\%C3\%A As_2004.pdf >. Acesso em 10 de Setembro de 2019.

- $\quad$ OLIVEIRA, ANA FLAVIA.Análise Ergonomica do Trabalho.Disponivel:< https://beecorp.com.br/blog/conheca-os-tipos-de-ergonomia/>. Acesso em 22 de Setembro de 2019.

- IIDA, ITIRO. Ergonomia: projeto e produção Ergonomia: projeto e produção Ergonomia: projeto e produção. São Paulo: Edgard Blücher, 2005. Disponivel:< https://www.passeidireto.com/arquivo/6399929/ergonomia-projeto-e-producao>.Acesso em 22 de Setembro de 2019. 
- $\quad$ ROCHA,HUGO. O que é Pesquisa Qualitativa, tipos, vantagens, como fazer e exemplos,2013. Disponível:< https://klickpages.com.br/blog/o-que-e-pesquisaqualitativa/>. Acesso em 23 de Setembro de 2019.

- DIANA,JULIANA. Pesquisa descritiva, exploratória e explicativa, 2017. Disponível:< https://www.diferenca.com/pesquisa-descritiva-exploratoria-eexplicativa/>. Acesso em 23 de Setembro de 2019.

- $\quad$ ARAUJO,ARINA.Postura ao se sentar..Brasilia,2014.Disponível:< http://www.arinaaraujo.com/blog/tag/postura-ao-se-sentar/>. Acesso em 24 de Setembro de 2019.

- WORKSOLUTION,Como reconhecer uma cadeira ergonômica, 2019.Disponível:< https://www.worksolution.ws/como-reconhecer-uma-cadeiraergonomica/>.Acesso em 26 de Setembro de 2019.

- $\quad$ BLOG SEGURANÇA DO TRABALHO, A importância do apoio para os pés no trabalho,2019.Disponível:<https://www.blogsegurancadotrabalho.com.br/2017/06/impor tancia-apoio-para-os-pes-no-trabalho.html>. Acesso em 30 de Setembro de 2019. 